Supporting information:

Long-term low DO operation decreases $\mathrm{N}_{2} \mathrm{O}$ emissions in the activated sludge process

Guoqiang Liu*, Xianwei Wu, Deyong Li, Lugao Jiang, Ju Huang, Li Zhuang

School of Environment, Guangdong Engineering Research Center of Water Treatment Processes and Materials and Guangdong Key Laboratory of

Environmental Pollution and Health, Jinan University, Guangzhou 510632, China

*Corresponding author: Guoqiang Liu, gqliu@jnu.edu.cn

This supporting information contains 11 pages, including 4 Figures and 1 Table. 


\section{S1. Reactor}

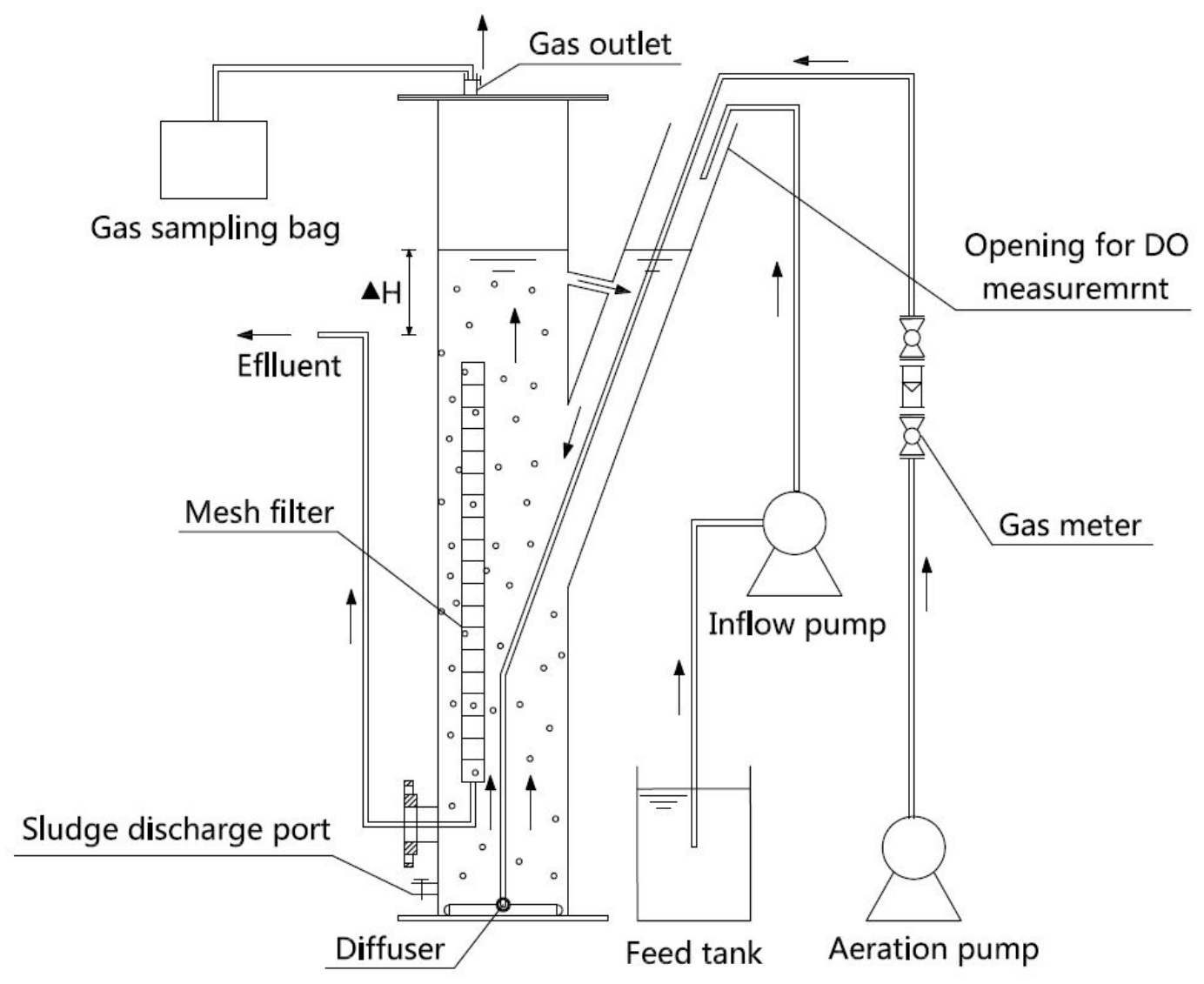

Figure S1 Schematic diagram for the bench scale bioreactor

The laboratory-scale membrane reactor $(12 \mathrm{~L})$ was set up as shown in Figure S1. A flat-sheet membrane module with filtration area of $0.068 \mathrm{~m}^{2}$ was submerged into the reactor. The 3-D printed frame was wrapped with nylon mesh, which had an averaged pore size of approximately $25 \mu \mathrm{m}$. The mesh was used as the support layer for dynamic membrane formation and as a result, the biomass was retained in the bioreactor with effluent turbidity less than 1.0 NTU. During the operation, the treated water passed the filter by the water head loss between the reactor water level and the outlet $(\Delta \mathrm{H})$ (Fig. S1). Along with the increasing filtration resistance, the water level in the reactor would increase 
to provide a greater transmembrane pressure (TMP) and then maintain the flux constantly. Once the operation TMP reached $2,500 \mathrm{~Pa}$, the membrane module was taken out and flushed with tap water.

A fine bubble diffuser was installed below the membrane module in each reactor. A gas flow meter was used to regulate the air flow rate to achieve the desired DO concentration. To collect the released air for $\mathrm{N}_{2} \mathrm{O}$ measurement, the reactor was sealed with an outlet for air releasing and sampling. On one side of the reactor, there is an opening for $\mathrm{DO}$ and temperature monitoring. 
S2. Other nutrients added into the influent

Table S1 Other nutrients added into the influent

\begin{tabular}{ccc}
\hline Elements & Concentration $(\mathrm{mg} / \mathrm{L})$ & Chemical \\
\hline $\mathrm{Mn}^{2+}$ & 0.2 & $\mathrm{MnCl}_{2} \cdot 4 \mathrm{H}_{2} \mathrm{O}$ \\
$\mathrm{Mo}^{5+}$ & 0.12 & $\mathrm{MoCl}_{5}$ \\
$\mathrm{Co}^{5+}$ & 0.001 & $\mathrm{CoCl}_{2} \cdot 6 \mathrm{H}_{2} \mathrm{O}$ \\
$\mathrm{Zn}^{2+}$ & 0.05 & $\mathrm{ZnCl}_{2}$ \\
$\mathrm{Fe}^{2+}$ & 0.005 & $\mathrm{FeSO}_{4} \cdot 7 \mathrm{H}_{2} \mathrm{O}$ \\
$\mathrm{Ca}^{2+}$ & 5.0 & $\mathrm{CaCl}_{2}$ \\
$\mathrm{Mg}^{2+}$ & 10.0 & $\mathrm{MgCl}_{2} \cdot 6 \mathrm{H}_{2} \mathrm{O}$ \\
Phosphorus & 2.0 & $\mathrm{~K}_{2} \mathrm{HPO}_{4} \cdot 3 \mathrm{H}_{2} \mathrm{O}$ \\
\hline
\end{tabular}


S3. Analysis methods for $\mathrm{DO}, \mathrm{MLSS}, \mathrm{pH}, \mathrm{NH}_{3}, \mathrm{NO}_{2}{ }^{-}$, and $\mathrm{NO}_{3}{ }^{-}$

The mixed liquor suspended solid concentration (MLSS) were determined using a gravimetric method. An Orion model $370 \mathrm{pH}$ meter with a PerpHecT pH electrode (Orion 9206BN) was used to measure the $\mathrm{pH}$. A YSI DO probe (550A) was used to measure DO. HACH test kits TNT $822 / 821$ were used to measure COD concentration. A HACH test kit TNT 832 was used to measure ammonia nitrogen concentration when it was higher than $2 \mathrm{mg}-\mathrm{N} / \mathrm{L}$ and a TNT 830 was used when it was lower than $2 \mathrm{mg}-\mathrm{N} / \mathrm{L}$. A HACH test kit TNT 840 was used to measure the nitrite- $\mathrm{N}$ concentration when it was higher than $0.6 \mathrm{mg}-\mathrm{N} / \mathrm{L}$ and a TNT 839 was used when it was lower than $0.6 \mathrm{mg}-\mathrm{N} / \mathrm{L}$. A HACH test kit TNT 835 was used to measure the nitrate- $\mathrm{N}$ concentration. 
S4. Biomass $\mathrm{AOR}_{\mathrm{m}}$ and $\mathrm{NOR}_{\mathrm{m}}$ measurements based on a respirometric methods

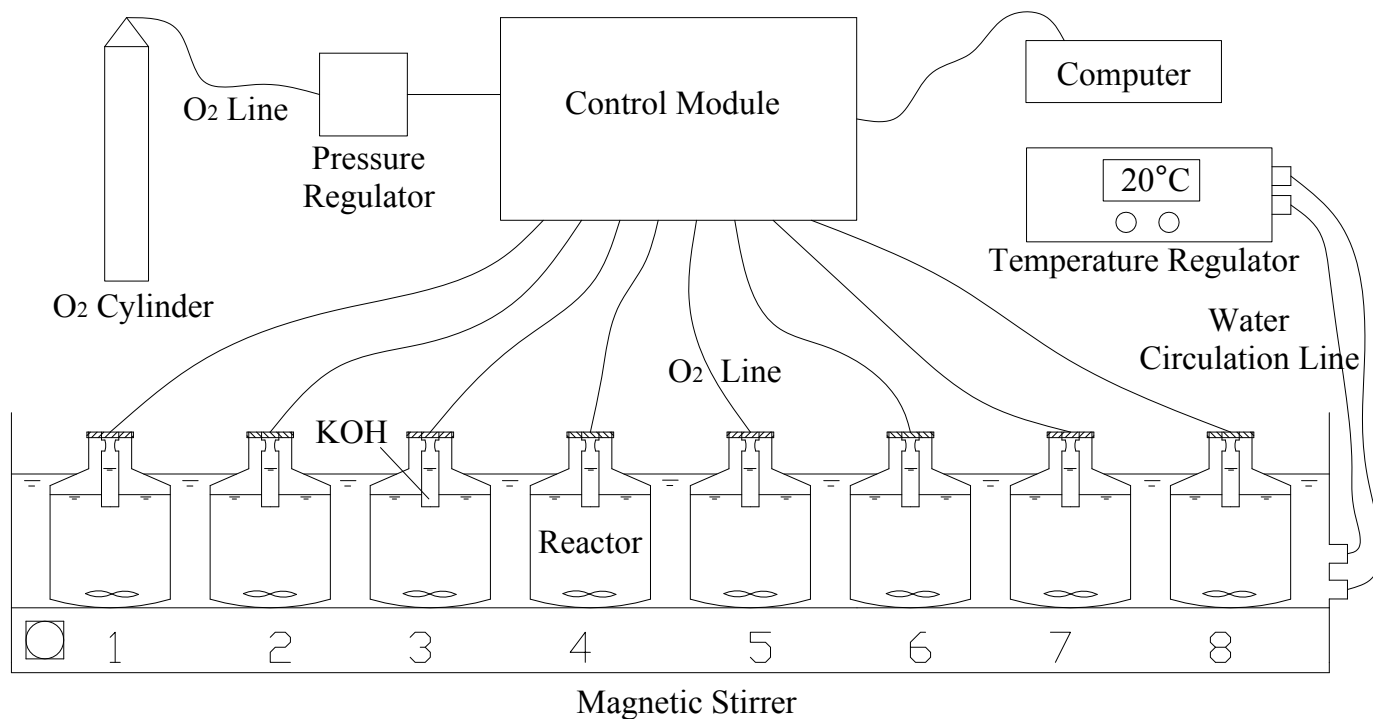

Figure S2 The setup for batch respirometric tests ${ }^{1}$

Batch respirometric tests (Figure S2) were conducted to determine the oxygen uptake rate (OUR) for complete nitrification and nitrite oxidation of sludge samples. In the tests, $500 \mathrm{~mL}$ of sludge sample were added into each batch reactor. After approximately 5 hours when the endogenous respiration rate in the reactor became constant, five $\mathrm{mL}$ of ammonium bicarbonate stock solution or sodium nitrite stock solution were added into each reactor to enhance the initial ammonia or nitrite concentration to approximately $30 \mathrm{mg}$ $\mathrm{N} / \mathrm{L}$. The $\mathrm{pH}$ was controlled at approximately 7.5 using a buffer solution containing $\mathrm{KH}_{2} \mathrm{PO}_{4}$ and $\mathrm{NaHCO}_{3}$. All reactors were intensively mixed with a magnetic mixer at $1200 \mathrm{rpm}$ to achieve a DO level greater than $4 \mathrm{mg} / \mathrm{L}$. The OUR was recorded every 6 minutes by a pulse-flow respirometer (RSA, USA). After all of the added substrate was consumed, the respiration rate decreased 
to the same level as it was before the substrate addition, and the batch test was terminated.

Based on Equation (1), the maximum ammonia oxidation rate can be estimated:

$$
A O R_{m}=\frac{O U R_{\max , N H}}{3.43-1.42 Y_{N H}}
$$

Similarly, the maximum nitrite oxidation rate can be estimated by Equation (2):

$$
N O R_{m}=\frac{O U R_{\max , N O}}{1.14-1.42 Y_{N O}}
$$

The maximum OUR for ammonia oxidation can be estimated based on Equation (3):

$$
O U R_{\max , N H}=O U R_{\max , N C}-O U R_{\max , N O}
$$

where, $\mathrm{AOR}_{\mathrm{m}}$, the maximum ammonia oxidation rate; $\mathrm{NOR}_{\mathrm{m}}$, the maximum nitrite oxidation rate; $O U R_{\max , N C}$, the maximum oxygen uptake rate for complete nitrification; OUR $\max , \mathrm{NH}$, the maximum oxygen uptake rate for ammonia oxidation; OUR $\max$ NO, the maximum oxygen uptake rate for nitrite oxidation; $\mathrm{Y}_{\mathrm{NH}}$, the yield coefficient for ammonia oxidizers, which is $0.18 \mathrm{~g}$-cell/g- $\mathrm{N}$ oxidized; ${ }^{1} \mathrm{Y}_{\mathrm{NO}}$, the yield coefficient for nitrite oxidizers, which is $0.06 \mathrm{~g}$-cell/g-N oxidized. ${ }^{1}$ 
S5: Estimating the observed rate of ammonia oxidizers under high-DO and low-DO

In activated sludge, it is difficult to directly measure the biomass concentration of active ammonia oxidizers in activated sludge. In this study, the active ammonia oxidizer biomass concentration can be calculated using Eq. (4) based on the measured $A_{O} R_{m}(140.4$ and $222.7 \mathrm{mg}-\mathrm{N} /(L \cdot d))$ and the previously determined $k_{\mathrm{NH}}$ value $\left(1.3 \mathrm{mg}-\mathrm{N} / \mathrm{mg}-\mathrm{VSS}-\mathrm{d}\right.$, respectively). ${ }^{2}$

$$
X_{N H}=\frac{A O R_{m}}{k_{N H}}
$$

where $X_{\mathrm{NH}}$ is the active biomass concentration of ammonia oxidizers, while $k_{\mathrm{NH}}$ is maximum specific ammonia utilization rate, $\mathrm{mg}-\mathrm{N} / \mathrm{d}-\mathrm{mg}-\mathrm{VSS}$.

According to Eq. (5), the observed yield rates for ammonia oxidizers are estimated to be 0.028 and $0.045 \mathrm{mg}-\mathrm{VSS} / \mathrm{mg}-\mathrm{N} \cdot \mathrm{d}$ in the high-DO and low-DO reactors, respectively.

$$
Y_{N H}=\frac{X_{A O B} \times V}{S R T \times N_{\mathrm{r}}}
$$

where $Y_{N H}$ is the observed yield rate for ammonia oxidizers; $V$ is the reactor volume (12 L); SRT is the solids retention time, which is 40 days; $N_{r}$ is the daily ammonia removal in both reactor, which is $1152 \mathrm{mg}-\mathrm{N} / \mathrm{d}$. 


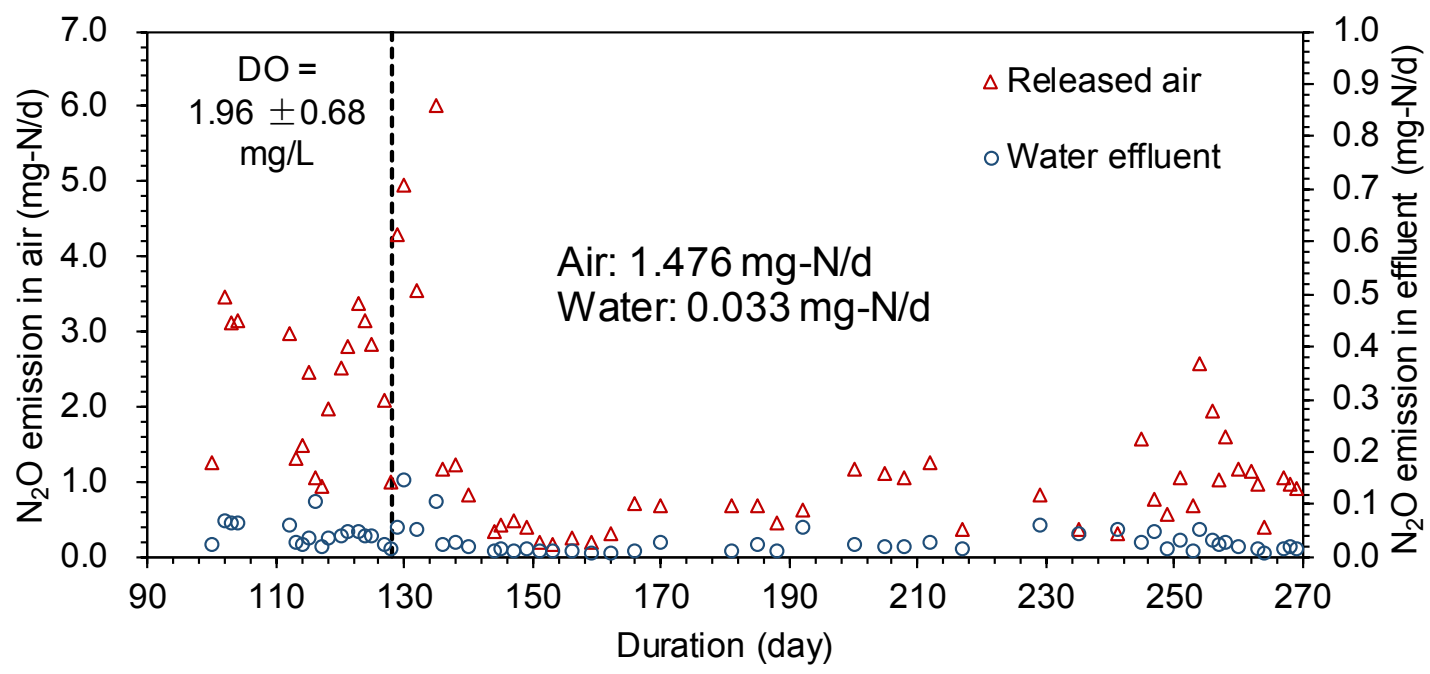

Figure S3 The emission rate of $\mathrm{N}_{2} \mathrm{O}$ in the released air and water effluent 


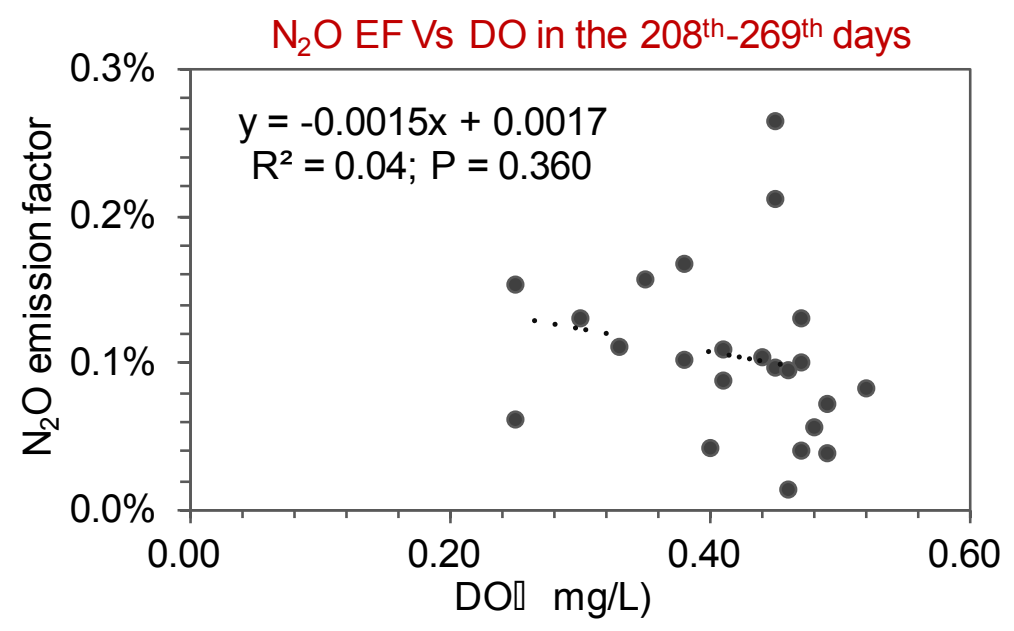

Figure S4 The correlation of $\mathrm{N}_{2} \mathrm{O}$ emission factor (EF) and dissolved oxygen (DO) concentration in the $208^{\text {th }}-269^{\text {th }}$ day under low DO operation 


\section{References:}

1. Liu, G. Q.; Wang, J. M. Probing the stoichiometry of the nitrification process using the respirometric approach. Water Res. 2012, 46, 59545962.

2. Liu, G. Q.; Wang, J. M. The role of solids retention time on complete nitrification: mechanistic understanding and modeling. J. Environ.

Eng. 2014, 140(1): 48-56. 